\title{
ESTÁGIO PÓS-DOUTORAL NO CANADÁ
}

\section{POST-DOCTORAL TRAINING IN CANADA}

\section{POS DOCTORADO DE CAPACITACIÓN EN CANADÁ}

\section{PROFESSOR DOUTOR JOSÉ ALONSO BORBA}

Universidade Federal de Santa Catarina (UFSC)

jalonso@cse.ufsc.br

Do final de 2007 até o início de 2009, realizei meu pós-doc na École dês Hautes Études Commerciales (HEC) de Montreal, no Canadá.

Montreal é a maior cidade da província canadense de Quebec, a segunda mais populosa do Canadá e também a segunda mais populosa cidade francófona do mundo, depois de Paris. É um dos principais centros comerciais e culturais da América do Norte. Montreal também possui uma considerável comunidade anglófona e um crescente número de imigrantes cujo idioma materno não é nem o francês nem o inglês. Além de ser considerada a cidade com características europeias, ela possui uma das populações mais bem-educadas do mundo e a maior concentração de estudantes universitários per capita de toda a América do Norte.

A escola é conhecida como HEC-Montreal, para se diferenciar das suas congêneres: HEC-Paris e HEC-Lausanne. Alguns programas e, principalmente, os doutorados da HECMontreal são realizados em conjunto com quatro universidades canadenses. A Université de Montreal, Université du Québec à Montreal (UQAM), Concordia University e a McGill University. Enquanto nas duas primeiras universidades a língua francesa predomina, nas outras duas é a língua inglesa. A escola não é uma universidade e poderíamos dizer que ela seria um tipo próximo à Fundação Getúlio Vargas (FGV).

A HEC-Montreal é uma escola internacional na área de negócios e que foi fundada em 1907. A escola se dedica ao ensino, à pesquisa e à extensão de assuntos ligados à área de negócios; tem, aproximadamente, 12.000 estudantes, sendo 3.600 estrangeiros, e, aproximadamente, 250 professores e 35 programas de estudo, desde cursos de graduação em Ciências Contábeis, Administração e outras áreas até mestrados e doutorados (PhD); e possui também 50 centros de pesquisa. Quando comparada com as escolas americanas, a HEC - Montreal está ranqueada em $16^{\circ}$ lugar entre as melhores escolas de negócios.

Um programa de pós-doutorado ou de estágio pós-doutoral, ou comumente chamado 
pós-doc, é realizado após o término do doutorado. O pós-doc tem por objetivo principal estimular pesquisadores a realizarem estágios para o desenvolvimento acadêmico e a consolidação de pesquisas. No Brasil, é normalmente financiado pelo CNPq e pela CAPES, além de fundações estaduais, como, por exemplo, a FAPESP. Pode ser realizado no Brasil ou no exterior. Diversos pesquisadores brasileiros que atuam na área de Contabilidade já fizeram pós-doc em diversas universidades pelo mundo ou mesmo no Brasil. Por exemplo, na University of Illinois, University of California - Berkeley, University of Otago, McGill University, Arizona State University, University of Kansas, Universidade de Coimbra, HEC-Montreal, FGV e USP.

De forma simplificada, para se candidatar, o interessado deverá ser doutor, desenvolver um plano de estudos, comprovar ser pesquisador atuante e ter carta de aceite da universidade e do orientador. Para requerer bolsa de estudos, tanto na CAPES quanto no CNPq, existem calendários predefinidos, e o pedido pode ser feito de janeiro a dezembro de cada ano.

As agências de fomento analisam o mérito do pedido e, caso aprovado, financiam a estada do pesquisador no exterior ou no Brasil. Além da bolsa, normalmente pagam passagens, auxílio instalação e seguro saúde. O estímulo para pós-doutoramento no Brasil tem aumentado muito. Somando-se a CAPES e o CNPq, tivemos 419 bolsas para todas as áreas em 2003 e, aproximadamente, 2.600 bolsas em 2009. Além disso, existem diversas fundações e instituições estrangeiras que patrocinam pós-doc, como, por exemplo, a Fulbright.

Em minha opinião, o pós-doutoramento deveria ser realizado em instituição diferente daquela na qual o pesquisador se doutorou. Acho fundamental conhecer outras realidades tanto nacionais quanto internacionais.

Já temos no Brasil diversos doutores em Contabilidade e um grande número de doutores de outras áreas que atuam, efetivamente, nos 19 programas de pós-graduação em Contabilidade e que contribuem para o desenvolvimento da área. Certamente, esses pesquisadores poderiam ser potenciais pós-doutorandos.

Isso certamente melhoraria nosso desempenho internacional. O Brasil está classificado em $13^{\circ}$ lugar em publicações internacionais de impacto se somarmos todas as áreas. Contudo, em Contabilidade, quando verificamos os principais accounting journals, parece que ainda não temos visibilidade, apesar da pujança econômica do Brasil.

Minha impressão é que isso tende a mudar. A Contabilidade, nos últimos anos, vem passando por mudanças drásticas as quais estão impactando a pesquisa, o ensino e a prática contábil. Os temas ligados aos estudos sobre transparência, evidenciação contábil, governança corporativa, accountability e harmonização de práticas contábeis, tanto da área privada quanto da área pública, estão sendo os vetores das novas pesquisas em Contabilidade. Tópicos específicos, como, por exemplo, valor justo, impairment, derivativos, contabilidade comportamental e as respectivas discussões teóricas vão, certamente, fazer renascer junto com estudos empíricos, estudos normativos e teóricos, os quais estavam esquecidos e ou eram pouco valorizados tanto pelas revistas nacionais quanto pelos journals internacionais. 
Tive a impressão, e acredito que não estou equivocado, de que o estágio pós-doutoral foi fundamental para compreender melhor como as pesquisas são e estão sendo desenvolvidas no exterior, além de constatar que não estamos tão distantes em termos de qualidade profissional e de pesquisa. Talvez nosso "Calcanhar de Aquiles" seja a pouquíssima produção científica internacional, que acaba inviabilizando debates, discussões e aprimoramentos de ambos os lados.

Finalmente, estão dispostas abaixo algumas poucas observações pessoais, as quais têm como intuito colaborar com o debate sobre algumas questões relativas à pesquisa em Contabilidade.

- $\quad$ Além do rigor científico, teremos que nos preocupar e ressaltar também a relevância prática de nossas pesquisas.

- Precisamos divulgar nossos achados também em jornais de grande circulação nacional e em revistas de conteúdo mais prático, para que os profissionais possam ler e entender melhor o que fazemos na academia.

- Precisaremos enfatizar e demonstrar a contribuição das nossas pesquisas para a melhoria das organizações e da sociedade brasileira.

- Precisamos descobrir onde a pesquisa contábil de qualidade tem sido publicada. Esta é uma questão controversa e aberta tanto no Brasil quanto no mundo. Muitas vezes, o status da revista é mais importante do que a qualidade do artigo nela publicado.

- Quando teremos um artigo com crítica, réplicas e tréplicas na mesma revista sem gerar animosidades, constrangimentos e falta de educação?

- Precisamos acabar com dogmas, principalmente alguns relacionados com a contabilidade financeira e mercados. Precisamos também criticar tanto os resultados quanto a sua relevância.

- $\quad$ Precisamos descobrir meios de revitalizar as pesquisas em contabilidade gerencial. Elas são tão importantes quanto as pesquisas em contabilidade financeira, mas existem menos periódicos dispostos a publicar essas pesquisas, principalmente quando não utilizam métodos quantitativos.

- $\quad$ Precisamos ser mais críticos com relação às pesquisas empíricas que utilizam sofisticadas técnicas estatísticas, nas quais a ferramenta utilizada parece ser mais importante do que o problema e os achados. Nosso campo de estudo é a Contabilidade.

- $\quad$ Precisamos de mais cientificidade nas pesquisas e de bancos de dados consistentes para que possamos, efetivamente, publicar em nível internacional.

- Apesar de a língua inglesa ser considerada a língua da ciência, precisamos publicar também em revistas da América Latina, Espanha, Portugal, etc. 